\title{
THE PUBLIC PERCEPTIONS TOWARDS SORENG DANCE AT LEMAHIRENG VILLAGE BAWEN SEMARANG
}

\author{
Anis Khairunnisa \\ Restu Lanjari
Graduate Students of Dance and Music Departement, Languanges and Arts Facull, Semarang State
University
Email: anisdewangga11@gmail.com

\begin{abstract}
Soreng dance is a kind of populist dance in the village Lemahireng. Dance Soreng describe the morale of the troops brave choice soldiers prepared for war games. Issues examined in this study are: Public perception of the Dance in the Village Lemahireng Soreng Bawen District of Semarang District. Goals to be achieved in this research is to determine the public perception in the village Lemahireng Bawen District of Semarang District and to determine the measures to be undertaken by the Department of Education and Culture. This study uses qualitative research methods and conduct research with a sociological approach method. Data were analyzed using data reduction, data presentation and conclusion. The results showed that of some perceptions obtained from the community about Tari Soreng. Perception is not present in the community to support children age (12-17 years) and younger age (17-25 years) and that support tends society in old age (25-85 years). Factors that affect the public perception of dance in the village Soreng Lemahireng Bawen District of Semarang District is the background for the birth of the perception of the community as a high level of education makes way people view more open and modern. The effort to do Office of Education and Culture of Semarang District is to provide guidance Dance Soreng should start with their own community in their respective regions, also carried out by a group of community Soreng kridho Wargo budhoyo, one form of effective formation is to hold a festival or competition. The conclusions of the study are: Problems sector in the public perception depends on your viewpoint and how to view an art. Dance Soreng perception of change in different elements of society Lemahireng village along with the advancement of age. Suggestions for the Education and Culture District of Semarang, to further maximize conservation efforts in the utilization of Dance Soreng in science and tourism. The younger generation is expected to be more easily studied dance Soreng and is expected to preserve and develop it.
\end{abstract}

Keywords : soreng Dance, public perceptions of lemahireng village;

\section{PENDAHULUAN}

Tari adalah salah satu bentuk cabang seni yang perlu dikembangkan dan dilestarikan. Tari bisa menjadi ciri khas dalam sebuah daerah. Tari merupakan salah satu bentuk budaya yang memiliki nilai atau makna dalam kehidupan di masyarakat. Berlatih tari dan bahkan mementaskan sebuah tarian secara tidak langsung telah melestarikan budaya.

Kesenian Tari Soreng merupakan kesenian kerakyatan yang berasal dari Kabupaten Semarang yang berada di provinsi Jawa Tengah. Definisi Tari Soreng adalah suatu kesenian kerakyatan yang di dalamnya mengandung unsur mistis, filosofis ideologi nusantara, moral, sejarah dan patriotisme yang telah ada sejak masa Raja pertama kesultanan Demak.

Kesenian Tari Soreng diciptakan untuk mengabdikan sejarah perjuangan Raja pertama
Kesultanan Demak yang mempunyai anak bernama Arya Penangsang yang memerintah pada pertengahan abad ke-16 yang dalam pemerintahannya diwakili patihnya yaitu Ki Metaun, pasukan prajurit yang gagah berani yang dipimpin oleh Arya Penangsang yang dalam melatih pasukan perangnya melawan penjajah.

Arya Penangsang mencerminkan sikap seorang pemimpin yang sangat hebat tersebut terdapat unsur-unsur nilai moral yang dalam melindungi masyarakat dalam jajahan. Sikap dan unsur-unsur nilai yang kita harus terapkan dalam kehidupan sehari-hari yaitu sikap tanggung jawab, kedisiplinan, kebersamaan, kekeluargaan dan sikap gotong royong.

Sikap dan unsur-unsur dari nilai moral dalam melindungi masyarakat dijajah sangatlah menarik untuk diteliti karena dalam kesenian Soreng terdapat unsur nilai moral yang dapat kita junjung 
tinggi terutama pada Desa Lemahireng Tari Soreng tidak ada perpecahan antar warga.

Awal berdirinya Tari Soreng di Desa Lemahireng Bawen yaitu karena Tari Soreng banyak tampil diacara hajatan warga setempat dan dikampung sekitarnya. Peguyuban atau sekelompok Tari Soreng bisa dikatakan sebagai seniman keturunan atau penerus dari para seniman-seniman terdahulu, yang pada dasarnya sudah memiliki bakat atau mengalir darah seni dari orang tua maupun keluarganya.

Tari Soreng ini mempunyai keistimewaan yaitu dalam unsur gerakan yang dimainkan sangat unik dan kompak, sehingga bisa menjadi daya tarik sendiri bagi masyarakatnya, tetapi masyarakat sebagaian belum paham, belum mengerti, belum mengetahui tetapi masyarakat berpersepsi yang berbeda-beda sebelum mereka mengetahuinya tentang apa itu kesenian Tari Soreng? Bagaimana wujudnya? Ada yang mengenal tetapi hanya sekedar mengenal, sebagian besar masyarakat, ada yang mengetahui dan ada yang tidak mengetahui apa itu sebenarnya Tari Soreng? didalam kesenian Soreng itu terdapat unsur-unsur mistis, filosofis ideologi nusantara, dan nilai moral untuk warga masyarakat terutama di Desa Lemahireng dan sekitarnya agar tidak ada perpecahan antar warga.

Penelitian diarahkan untuk menggali Persepsi masyarakat Desa Lemahireng terhadap Tari Soreng dan faktor-faktor apa saja yang mempengaruhi persepsi masyarakat terhadap Tari Soreng. Berdasarkan uraian diatas, maka peneliti tertarik untuk melakukan penelitian dengan judul "Persepsi Masyarakat Terhadap Tari Soreng".

Bedasarkan uraian di atas, permasalahan yang dapat diuraikan untuk membahas Persepsi Masyarakat Terhadap Tari Soreng Di Desa Lemahireng Bawen Kabupaten Semarang dapat dirumuskan dalam pertanyaan: bagaimana persepsi masyarakat terhadap Tari Soreng di Desa Lemahireng Bawen Kabupaten Semarang ?, dengan kajian pokok (1) faktor-faktor apa saja yang mempengaruhi persepsi masyarakat terhadap Tari Soreng di Desa Lemahireng Bawen Kabupaten Semarang?

Menurut Slameto (2003: 102) Persepsi adalah proses yang menyangkut masuknya pesan atau informasi ke dalam otak. Melalui persepsi manusia terus menerus mengadakan hubungan dengan lingkungannya, hubungan ini dilakukan lewat indranya, yaitu indera penglihatan, pendengar, peraba, perasa dan pencium.

Persepsi menurut Sudiana, Dendi (1986: 11) adalah proses seseorang dalam memelihara kontak dengan lingkungannya atau suatu proses penerimaan rangsang indrawi dan penafsirannya berkaitan dengan hal tersebut. Kartini Kartono (1984:77) menerangkan bahwa persepsi adalah pengamatan secara global yang belum disertai kesadaran, subjek dan objeknya pun belum di bedakan. Persepsi menurut Lindzey Gardner dan Aronzon (1973:395) yang maksud dengan persepsi adalah bagaimana seseorang memandang atau mengetahui ciri-ciri atau sifat-sifat pihak lain.

Diterangkan bahwa persepsi bermula dari biologi, yang berarti dari kegiatan indra kita mendapat rangsangan dari sesuatu objek yang visual, kemudian konsep tersebut digunakan oleh ilmuan jiwa yang berbagi pengetahuan seseorang mengenai sesuatu objek. Pada dasarnya persepsi muncul karena ada kesadaran terhadap lingkungan melalui sebuah proses mental yang menjadikan adanya interaksi antara objek dengan persepsi dapat dipengaruhi banyak faktor.

Proses persepsi seseorang terbentuk melalui langkah-langkah : (a) adanya rangsang/ stimulus, (b) proses pengumpulan informasi-informasi, (c) proses seleksi, yaitu menentukan apa yang harus dicatat dalam suatu informasi, (d) proses pengkombinasian informasi, antara informasi yang satu dengan yang lainnya dihubung-hubungkan dan dikaitkan dengan pengalaman yang telah dimiliki, (e) proses pengorganisasian informasi ke dalam pola-pola tertentu, dan (f) proses penginterpretasian informasi yang telah berpola kedalam sesuatu yang bermakna. (Neisser dalam Atkinson, 1987: 223).

Persepsi dipengaruhi oleh beberapa faktor, yakni pengalaman individu, proses belajar, cakrawala dan pengetahuan individu. Apabila persepsi pada seseorang telah terbentuk, maka seseorang akan memiliki atau memutuskan suatu sikap pada obyek yang dipersepsi (Mar'at 2004: 07).

Masyarakat berasal dari kata musyarak (Arab) yang artinya bersama-sama. Kemudian berubah menjadi masyarakat yang artinya berkumpul bersama, hidup bersama dengansaling berhubungan dan saling mempengaruhi, selanjutnya mendapatkan kesepakatan menjadi masyarakat (Indonesia) Abdul Syani (1987:30). Masyarakat dapat membentuk kepribadian yang khas bagi manusia, sehingga tanpa adanya kelompok manusia tidak akan mampu berbuat banyak dalam kehidupanya.

Masyarakat adalah golongan besar atau kecil yang terdiri dari beberapa manusia yang dengan paksaan atau sendirinya bertalian secara golongan dan pengaruh mempengaruhi satu sama lain. Pendapat lain, masyarakat adalah sistem cara kerja dan prosedur dari otoritas dan saling membantu yang meliputi kelompok-kelompok dan pembagian sosial lain, sistem dari pengawasan 
tingkah laku manusia dan kebebasan (Shadily 1993: 47-50).

Istilah masyarakat kota terbentuk dari dua buah kata yaitu kata "masyarakat" dan kata "kota". Masyarakat atau society adalah sejumlah ,manusia yang terikat pada satu kebudayaan tertentu yang sama, sedangkan "kota" memiliki definisi yang berbeda. Menurut kamus istilah Antropologi, "kota" adalah bentuk pemukiman yang padat penduduknya dengan sistem teknologi, ekonomi, organisasi sosial dan administrasi yang berkapasitas tinggi untuk menyediakan jasa dan mengatur kehidupan manusia yang tak terbatas besarnya. (Solikatun 2011: 15).

Tari tradisional kerakyatan adalah tari yang tumbuh secara turun-menurun dalam lingkaran masyarakat etnis, atau berkembang dalam rakyat, untuk itu seringkali sebutan Folkdance. Tari kerakyatan merupakan kelanjutan dari tarian primitif yang bersifat magis dan sakral.

(Sedyawati 1991: 10).

Seni rakyat adalah bagian dari kebudayaan rakyat yang merupakan seni yang berkembang di desa-desa di luar istana atau pusat-pusat kesenian yang biasa menopang timbulnya budaya agung. Seni rakyat yaitu komunitas seninya masih akrab, homogen dan justru berfungsi untuk mengikat solidaritas komunitas. Ciri-ciri tari rakyat yaitu: 1) bentuknya tradisional merupakan ekspresi kerakyatan, 2) pengembangan dari tarian primitif, 3) bersifat komunal (kebersamaan), 4) gerak dan polanya masih sederhana dan sering diulang-ulang (Jazuli 2002: 63).

\section{METODE PENELITIAN}

Penelitian pada Persepsi masyarakat terhadap Tari Soreng merupakan penelitian dengan menggunakan metode kualitatif dengan sifat deskriptif. Jenis penelitian ini bersifat deskriptif karena penelitian ini bertujuan untuk mendeskrisikan persepsi masyarakat terhadap Tari Soreng dan faktor-faktor apa saja yang mempengaruhi persepsi masyarakat terhadap Tari Soreng.

Penelitian yang berjudul Persepsi masyarakat terhadap Tari Soreng. Dilihat dari permasalahan yang telah dirumuskan, peneliti melakukan penelitian dengan menggunakan metode pendekatan Sosiologis. Sosiologis penelitian yang bertujuan untuk memperjelas keadaan yang sesungguhnya di masyarakat terhadap masalah yang diteliti.

Data yang diambil dalam penelitian ini berlokasi di Desa Lemahireng Kecamatan Bawen Kabupaten Semarang.. Objek penelitian berupa persepsi masyarakat yang ada di Desa Lemahireng Bawen Kabupaten Semarang. Data dan informasi yang diperlukan maka ditentukan sumber data dan informasi yang terdiri dari narasumber yang dipandang memiliki pengetahuan, wawasan dan informasi dari masalah yang dikaji. Narasumber tersebut yaitu Kepada pencipta, pemusik, pelaku seni dan penonton.

Teknik pengumpulan data yang digunakan meliputi observasi, wawancara, dan dokumentasi (Rohendi 2011: 180-213). Pemeriksaan keabsahan data dalam penelitian ini menggunakan teknik triangulasi.Teknik triangulasi yang digunakan dalam penelitian ini adalah triangulasi sumber yakni dengan cara membandingkan data hasil pengamatan dengan data hasil wawancara.

\section{HASIL PENELITIAN DAN PEMBAHASAN}

Soreng merupakan kesenian tradisional yang sangat jarang diketahui oleh masyarakat, karena kesenian tradisional Soreng ini baru ada 5 tahun terakhir di daerah Kabupaten Semarang, karena jarang peminatnya sehingga Tari Soreng dilupakan oleh masyarakat, tetapi pada zaman dahulu Tari Soreng pernah sangat eksis dikalangan masyarakat tertentu yaitu di daerah Kabupaten Temanggung, sedangkan Tari Soreng kridho wargo budhoyo ini pertama kali dikenalkan oleh masyarakat umum di Dusun Klarangan Desa Lemahireng Kecamatan Bawen Kabupaten Semarang.

Awal berdirinya kesenian Soreng tepatnya pada tanggal 24 juni 2005 yang dipelopori oleh Bapak Slamet (Bledek), beliau sudah lama menetap di Dusun Klarangan Desa Lemahireng, berawal dari berdirinya Soreng di Desa Lemahireng yaitu banyak undangan tampil di acara hajatan warga setempat dan dikampung sekitarnya. Kesepakatan warga Soreng sejak 1 tahun pertama Soreng diresmikan oleh Dinas Pendidikan dan Kebudayaan pada tanggal 1 Desember 2014 sejak itulah Soreng dinobatkan menjadi asset kesenian tradisional milik warga Dusun Klarangan RW IV.

Soreng berasal dari kata suro dan ing yang bermakna berani dan ing adalah pada, jadi maksudnya suro-ing mempunyai makna pada berani atau bisa diartikan pemberani, ada juga yang mengatakan soroking yang bermakna menyorok atau mendorong, maksudnya mendorong semangat keberanian mentalis prajurit. (Puji Wahyuti, 2010:40-41). Simbol keberanian soreng terlihat dari warna pakaiannya yaitu mencolok warna merah.

Secara simbolik soreng menunjukan sosok pasukan perang yang pilih tanding dan pemberani. Secara garis besar Tari Soreng adalah kumpulan pasukan pilihan yang siap untuk berperang laga. 
Persepsi Masyarakat terhadap Tari Soreng di Desa Lemahireng Kecamatan Bawen Kabupaten Semarang

Persepsi adalah kesan mengenai apa yang diamati yang didapat melalui indera, baik secara bersama-sama ataupun sendiri-sendiri, bermula dari adanya suatu tindakan pengamatan yang menghasilkan suatu kesan sehingga menimbulkan kesadaran bagi pengamat yang dapat dikembangkan pada masa sekarang ataupun menjadi antisipasi pada masa yang akan datang.

observasi dan wawancara di Desa Lemahireng guna memperoleh persepsi masyarakat yang dilaksanakan selama sebulan lebih dari tanggal 30 Desember 2015 sampai 31 Januari 2016, observasi dilakukan dengan cara mendatangi warga dan tokoh masyarakat sesuai responden dan sasaran yang akan diteliti. Wawancara dilakukan berdasarkan pedoman wawancara yang telah peneliti buat sebelumnya sesuai dengan tujuan penelitian.

Peneliti melakukan wawancara tentang persepsi masyarakat terhadap Tari Soreng di Desa Lemahireng Kecamatan Bawen Kabupaten Semarang, dengan membagi menjadi 3 golongan anak usia 12-17 tahun, golongan muda usia 17-25 tahun, dan golongan tua usia 25-85 tahun yang meliputi aparetur pemerintahan desa, tokoh masyarakat, tokoh agama, para generasi muda karang taruna, dengan wawancara "Apa yang bapak/ibu ketahui tentang Tari Soreng Kridho Wargo Budhoyo? Apakah bapak/ibu menyukai kesenian tradisional kerakyatan Soreng?

Tari Soreng di Desa Lemahireng Kecamatan Bawen mendatangkan banyak persepsi dari masyarakat yang meliputi Kepala Kelurahan Desa Lemahireng, Pimpinan kelompok Tari Soreng, Tokoh Masyarakat Desa Lemahireng, Seniman Tari Soreng. Persepsi yang diberikan oleh masyarakat sangat beraneka ragam. Tari Soreng ini mempunyai keistimewaan yaitu dalam unsur gerakan yang dimainkan sangat unik dan kompak, sehingga bisa menjadi daya tarik sendiri bagi masyarakatnya.

Persepsi yang tidak mendukung terdapat pada pada masyarakat usia anak-anak (12-17 Tahun) dan usia muda (17-25 Tahun) Pada masyarakat kalangan usia muda Tari Soreng masih dianggap klenik dan perkembangan IPTEK semakin bertambah maju sehingga untuk masyarakat pada usia muda sudah malas dan kurang berminat untuk mendukung, atau terjun langsung untuk mempelajari ataupun sekedar rasa ingin mengetahui, dan tidak terlibat langsung pada pelestarian, sehingga kurangnya motivasi untuk kalangan usia muda lainnya, karena untuk belajar untuk kalangan usia muda tidak ada pempublikasian, dan tidak diberi kesempatan selalu terlibat langsung dalam kesenian dan yang mendukung cenderung masyarakat pada usia tua (25-85 Tahun), karena pada usia tua masih sering mempertunjukan kesenian Tari Soreng, dan hanya di desa Lemahireng yang masih ada paguyuban Soreng sendiri sehingga tetap berkumpul, akan tetapi ada suatu penghambatnya dari pihak Paguyuban Tari Soreng yaitu kurang mempublikasikan keluar karena rendahnya penggunaan teknologi pada pihak pengelola Paguyuban Tari Soreng yang ada di Desa Lemahireng.

Faktor-faktor yang Mempengaruhi Persepsi masyarakat terhadap Tari Soreng di Desa Lemahireng Kabupaten Semarang

Persepsi yang lahir di berbagai macam lapisan masyarakat Desa Lemahireng Kecamatan Bawen Kabupaten Semarang mulai dari masyarakat yang tahu tentang seni contohnya kalangan intelektual, kemudian masyarakat yang tidak tahu tentang seni contohnya tokoh masyarakat awam, kemudian aparatur desa, dan pelaku seni, banyak faktor-faktor yang melatar belakangi lahirnya persepsi masyarakat terhadap Tari Soreng ini.

Faktor-faktor yang mempengaruhi persepsi masyarakat terhadap Tari Soreng di Desa Lemahireng Kecamatan Bawen Kabupaten Semarang adalah persepsi yang lahir dari berbagai macam lapisan masyarakat Desa Lemahireng mulai dari kalangan intelektual, aperatur desa, tokoh agama, masyarakat awam, anak-anak dan remaja (Usia 12-17 tahun) membuktikan bahwa banyak faktor-faktor yang melatar belakangi lahirnya persepsi itu.

Faktor yang mendukung adanya Tari Soreng yaitu dari Kalangan Intelektual dengan tingkat pendidikan yang tinggi mempunyai pemikiran yang lebih maju, dan modern, itu disebabkan karena pengetahuan yang mereka miliki bukan hanya sebatas dilingkungan daerahnya saja tetapi daerah-daerah lain, begitu juga dengan kesenian yang mereka lihat dari daerah-daerah lain, mereka semakin terbuka dalam menafsirkan kesenian di daerahnya sendiri, selain itu juga kemajuanIlmu Pengetahuan dan Teknologi (IPTEK) seperti internet mendukung pola fikir masyarakat kalangan intelektual.

Faktor-faktor menghambat Tari Soreng di Desa Lemahireng yaitu dikarenakan lingkungan Desa Lemahireng yang terbilang religious dengan mayoritas penduduknya menganut agama Islam menjadikan kesenian yang selalu berpatokan pada ajaran Islam. Para tokoh agama yang memegang kuat kaidah-kaidah ajaran agama Islam berusaha untuk menyeleksi semua bentuk kesenian yang ada di Desa Lemahireng. 


\section{SIMPULAN}

Berdasarkan hasil penelitian dapat disimpulkan, terjadinya perbedaan persepsi terhadap Tari Soreng antar golongan dari masyarakat Desa Lemahireng dan berbagai macam faktor yang melatar belakangi lahirnya persepsi dimasyarakat. Tari Soreng di Desa Lemahireng Kecamatan Bawen mendatangkan banyak persepsi dari masyarakat yang meliputi Kepala Kelurahan Desa Lemahireng, Pimpinan kelompok Tari Soreng, Tokoh Masyarakat Desa Lemahireng, Seniman Tari Soreng.

Persepsi yang diberikan oleh masyarakat sangat beraneka ragam, seperti Persepsi yang mendukung dan tidak mendukung. Persepsi yang tidak mendukung terdapat pada pada masyarakat usia anak-anak (12-17 Tahun) dan usia muda (17-25 Tahun) Pada masyarakat kalangan usia muda Tari Soreng masih dianggap klenik dan perkembangan IPTEK semakin bertambah maju sehingga untuk masyarakat pada usia muda sudah malas dan kurang berminat untuk mendukung, atau terjun langsung untuk mempelajari ataupun sekedar rasa ingin mengetahui, dan tidak terlibat langsung pada pelestarian, sehingga kurangnya motivasi untuk kalangan usia muda lainnya, karena untuk belajar untuk kalangan usia muda tidak ada pempublikasian, dan tidak diberi kesempatan selalu terlibat langsung dalam kesenian dan yang mendukung cenderung masyarakat pada usia tua (25-85 Tahun), karena pada usia tua masih sering mempertunjukan kesenian Tari Soreng, dan hanya di desa Lemahireng yang masih ada paguyuban Soreng sendiri sehingga tetap berkumpul, akan tetapi ada suatu penghambatnya dari pihak Paguyuban Tari Soreng yaitu kurang mempublikasikan keluar karena rendahnya penggunaan teknologi pada pihak pengelola Paguyuban Tari Soreng yang ada di Desa Lemahireng.

\section{SARAN}

Saran yang dapat peneliti ungkapkan mengenai Persepsi Masyarakat Terhadap Tari Soreng di Desa Lemahireng Kecamatan Bawen Kabupaten Semarang, sebagai berikut :

Bagi pelaku dan seniman kelompok Paguyuban Kridho Wargo Budhoyo, lebih meningkatkan pelatihan-pelatihan tari khususnya Tari Soreng, selanjutnya hendaknya lebih dapat membuka wawassan yang luas, dan disertai pemanfaatan alat modern serta melibatkan masyarakat usia muda guna memperluas ide dan daya tarik Tari Soreng.

Upaya pengenalan dan pelestarian kesenian tradisional Tari Soreng kepada generasi muda oleh Pemerintah Daerah Kabupaten Semarang hendaknya lebih luas lagi lingkupnya dan dukungan aktif dari paguyuban.

Pemerintah memiliki peran yang sangat strategis dalam upaya pelestarian kebudayaan daerah di tanah air. Pemerintah Daerah diharapkan dapat mengimplementasikan kebijakan-kebijakan yang mengarah pada upaya pelestarian kebudayaan daerah.

\section{References}

Ambarwangi, S., \& Suharto, S. (2014). REOG AS MEANS OF STUDENTS' APPRECIATION AND CREATION IN ARTS AND CULTURE BASED ON THE LOCAL WISDOM. Harmonia: Journal Of Arts Research And Education, 14(1), 37-45. doi:http://dx.doi.org/10.15294/harmonia.v14i 1.2789

Arikunto, Suharsini. 2006. Prosedur Penelitian Suatu Pendekatan Praktik. Jakarta: PT. Rineka Cipta.

Bastomi, Suwaji. 2004. Apresiasi Seni Tari. Semarang: SENDRATASIK UNNES

Barker, Chris. 2000. Cultural Studies (Theory and Practice. London: Yogyakarta: Kreasi Wacana

Cahyono, Agus. 2006. Seni Pertunjukan Arakarakan dalam Upacara Tradisional Dugdheran di Kota Semarang Jurnal Pengetahuan dan Pemikiran Seni Harmonia Vol.II No.3. Semarang: SENDRATASIK. Cipta.

Damono. 1998. Masyarakat dan Sosiologi Seninya. Jakarta: Pusat Perkembangan Depdikbud.

Djadjoni. 1985. Seluk Beluk Masyarakat Kota. Bandung: Alumni.

Jazuli, M. (2015). Aesthetics of Prajuritan Dance in Semarang Regency. Harmonia: Journal Of Arts Research And Education, 15(1), 16-24. doi:http://dx.doi.org/10.15294/harmonia.v15i 1.3692

Djelantik, A.A.M. 1999. Estetika Sebuah Pengantar. Bandung: Masyarakat Seni Pertunjukan. 
Hadi, Sumandiyo. 2005. Sosiologi Tari Sebuah Pengenalan Awal. Yogyakarta: Pustaka Jaya

Kulsum, umi, dan Jauhar, mohammad. 2014. Psikologi Sosial. Jakarta: Prestasi Pustakaraya.

Koentjaraningrat. 1977. Metode-Metode Penelitian Masyarakat. Jakarta: PT. Gramedia

1984. Kebudayaan Jawa. Jakarta: PN. Balai Pustaka

2002. Manusia dan Kebudayaan di Indonesia. Jakarta: PT. Gramedia

Djambatan Anggota IKAPI 2011. Sosiologi Seni (Pengantar dan Model Studi Seni), Jurnal Pola Pewarisan Kesenian Soreng Dalam Komunitas Seni "Wargo Budhoyo" Di Dusun Gejayan Desa Banyusidi Kecamatan Pakis Kabupaten Magelang. Semarang: SENDRATASIK

Hidajat, Robby. 2005. Wawasan Seni Tari (Pengetahuan Praktis bagi Guru Seni Tari). Malang: Jurusan Seni dan Desain Fakultas Sastra UNM

Wadiyo. 2008. Sosiologi Seni (Sisi Pendekatan Multi Tafsir). Semarang: SENDRATASIK UNNES

Yasyin, Sulchan. 1997. Kamus Lengkap Bahasa Indonesia. Surabaya: AMANAH

Kanisius. 2005. Teori-Teori Kebudayaan. Yogyakarta: Balai Pustaka

Kuntowijoyoyo. 1987. Budaya dan Masyarakat. Yogyakarta: PT. Tiara Wacana Yogya.

Indriyanto. 2010. Analisis Tari. Semarang: UNNES PRESS.

Jazuli, M. 2001. Metode Penelitian Kualitatif. Semarang: UNNES PRESS.

2002. Telaah Teoritis Seni Tari. Semarang: UNNES PRESS.

2008. Paradigma Kontekstual Pendidikan Seni. Semarang: UNNES Press.
2008. Pendidikan Seni Budaya "Suplemen Pembelajaran Seni Tari”. Semarang: UNNES Press.

Malarsih, M. (2016). The Tryout of Dance Teaching Media in Public School in The Context of Appreciation and Creation Learning. Harmonia: Journal Of Arts Research And Education, 16(1), 95-102. doi:http://dx.doi.org/10.15294/harmonia.v16i 1.4561

Malarsih, M., \& Herlinah, H. (2014). Creativity Education Model through Dance Creation for Students of Junior High School. Harmonia: Journal Of Arts Research And Education, 14(2), 147-157. doi:http://dx.doi.org/10.15294/harmonia.v14i 2.3296

Mariasa, I. (2015). Taksu and Pangus As An Aesthetic Concept Entity of Bali Dance (A Case Study of Topeng Tua Dance). Harmonia: Journal Of Arts Research And Education, 15(2). doi:http://dx.doi.org/10.15294/harmonia.v15i 2.4557

Santosa, D., Dewi, G., \& Rahayu, A. (2017). Lawet dance and ebleg dance: the term analysis towards its movement qualities. Harmonia: Journal Of Arts Research And Education, 17(1), 31-40. doi:http://dx.doi.org/10.15294/harmonia.v17i 1.7805

Miles, B. Matthew dan A. Michael Huberman. 1992. Analisis Data Kualitatif. Jakarta: Universitas Indonesia.

Moeleong, Lexy. 2007. Metode Penelitian Kualitatif. Bandung: PT Remaja Rosdakarya.

Prasetyo, Joko Tri. 2009. Ilmu Budaya Dasar. Jakarta: PT Rineka Cipta.

Rahardiana, Nurul. 2006. "Persepsi Siswa SMP N 8 Semarang Terhadap Tari Tradisional". Skripsi. Semarang: UNNES.

Suwardi, Endraswara. 2006. Metode, Tari, Teknik Penelitian Kebudayaan. Yogyakarta: Pustaka Widyatama.

Susetyo, Bagus. 2007. Pengkajian Seni Pertunjukan Indonesia. Semarang: SENDRATASIK.

Sumanti, Titi. 2009. "Persepsi Masyarakat Sidomulyo Kecamatan Jekulo Kabupaten 
Kudus terhadap Kesenian Tayub dalam Upacara Ritual Adat Bersih". Skirpsi. Semarang: UNNES.

Sugiyono. 2008. Metode Penelitian Kuantitatif, Kualitatif dan R\&D. Bandung: Alfabeta. 2011. Metode Penelitian Kuantitatif, Kualitatif dan R\&D. Bandung: Alfabeta.

Solikatun 2011. "Kepedulian Masyarakat Kota Dalam Menjaga Eksistensi Kota". Skripsi. Semarang: UNNES.
Soekanto, Soerjono. 2014. Sosiologi Suatu Pengantar. Jakarta: Raja Grafindo Persada. 1990. Masyarakat dan Perilakunya. Jakarta: PT Rajawali.

Soedarsono, R. M. 1998. Seni Pertunjukan Indonesia dan Era Globalisasi. Yogyakarta: Gajahmada University Press.

Sedyawati, Edi. 1991. Tari. Jakarta: Pustaka Jaya.

Soedarso. 1991. Perkembangan Kesenian Kita. Yogyakarta: BP ISI Yogyakarta. 